\title{
New Media-based Health Communication in China-An empirical investigation aimed at innovation of new media
}

\author{
Yi DING ${ }^{1, \text { a }}$, Jian $\mathrm{DU}^{2, \mathrm{~b}}$ \\ ${ }^{1}$ School of Design Art \& Media Nanjing University of Science and Technology Nanjing, CHINA \\ ${ }^{2}$ Graduate School of Human-Environment Studies Kyushu University Fukuoka, JAPAN
}

\begin{abstract}
In this research, an empirical investigation is made to analyze the operation mode, effect, and feedback of digital health communication, which is based on China's new media, and the result shows that: firstly, although the common new media's means of communication are diverse and the profit mode is varied, traditional means such as articles and videos still prevail. Yet, new media has a heavy dependence on the profit mode based on network advertising and online shopping, while the operation mode profiting by outputting high-quality content requires a further improvement; secondly, on the whole, no obvious difference is found in the effect of communication between people of different ages and genders, but the main difference is observed between people having health problems and those not. If an in-depth analysis is respectively conducted for different kinds of new media, some specific differences can be found in the communication effect; thirdly, although many audiences may concern about the risks brought by new media's credibility and commercial factors, commercial operation in a standardized way is acceptable to a large number of audiences. Therefore, effort shall be made to propel the development of new media-based health communication from such perspectives as optimizing the operation mode, deepening the user research and regulating the commercial operation, etc.
\end{abstract}

\section{Background and Purpose}

Originating from the 1970 s, the research on health communication is applied to the combination of health promotion and communication [1]. For the specific definition of health communication, Rogers's explanation has been widely accepted by the world. Namely, "health communication is any type of human communication whose content is concerned with health" [2]. This definition academically extends the fields covered by health communication and integrates Health Preservation \& Fitness, Exercise Training, and Medical Treatment \& Nursing into the scope. In the practical theory of health communication, the theory of Knowledge, Attitude, and Practice (hereinafter referred to as KAP Theory) are widely adopted to explain how the knowledge and faith that people gain influence the change of health behaviors [3]. In many research related to health communication, KAP Theory is applied to measure the health communication effect from the aspects of Knowledge, Attitude, and Practice and discuss the means of health communication [4].

With the rapid growth of China's mobile Internet industry, new media has broken through the existing mode of traditional media, such as television, radio, newspapers, books, and magazines. As a result, the status of health communication has changed significantly. New media is the channels and platforms for producing, disseminating, displaying, and storing information and entertainment that rely on digital communication technologies with the computer at the core [5]. New Media-based Health Communication (or Digital Health Communication) is pluralistic, interactive, precise, and efficient [6]. On one hand, the access threshold of health communication is lowered and most communicators can enter the health communication field at a lower cost, enriching the content of this field. On the other hand, the existing new mediabased health communication is fragmented and decentralized and encounters other problems [7]. In this field full of opportunities and risks, it is required to proceed from the development status of new media-based health communication and work out various optimization strategies positioned to some prominent problems.

In this research, some typical cases are selected from China's new media. From such perspectives as Operation Mode (including transmission mode and profit mode), Effect (new media's impact on the audience's KAP), and Feedback (including the audience's comments and expectation on new media), an empirical investigation is carried out to analyze the development status of new media-based health communication in China. On this basis, various optimization strategies geared to the innovation of new media-based health communication are discussed. 


\section{Operation Mode of New Media-based Health Communication}

In China, among various new media applied for health communication, WeChat, Tiktok and Sina Weibo, etc. have currently achieved a higher level of popularization. Although the health APP is supposed not to be included in new media, it substantially possesses the new media's attribute in reality as it will disseminate many kinds of health information to the user. In terms of all kinds of new media, their operation modes vary due to the difference in product positioning, platform limitations, and user structure. For the new media' operation mode, researchers have performed corresponding research from various perspectives, but in the content, it involves two aspects at least: how the information is spread and how the profit is earned from information spread. Hence, the operation mode will be discussed mainly from the perspectives of transmission mode and profit mode in this research.

\subsection{Target and Method}

This research targets at 4 common new media (WeChat, Tiktok, Sina Weibo APP) applied to health communication. Through searching various keywords such as healthcare, health preservation, health management, fitness, and selfcare via the public account of WeChat, Tiktok, Sina Weibo, and Huawei AppGallery, the accounts inconsistent with the definition of health communication are excluded while Top 10 most popular accounts or APPs are screened out as typical cases. Then, the content analysis is conducted to extract and analyze the transmission mode and profit mode, on which basis, the common operation mode of new media-based health communication is summarized.

\subsection{Common Operation Modes of New Media- based Health Communication}

According to the investigation result, 40 typical cases exerting extensive influence are extracted from 4 kinds of common new media, and relevant information is listed by using content analysis. Related data are valid till September 3, 2020.

Table I Public account of WeChat applied to health communication

\begin{tabular}{|c|c|c|}
\hline Case & $\begin{array}{c}\text { Transmission } \\
\text { Mode }\end{array}$ & Profit Mode \\
\hline 1 & Article, Video & $\begin{array}{l}\text { Network Advertising, Paid } \\
\text { Reading and Telemedicine }\end{array}$ \\
\hline 2 & Article, Video & Paid Reading \\
\hline 3 & Article & $\begin{array}{l}\text { Network Advertising, Online } \\
\text { Shopping }\end{array}$ \\
\hline 4 & Article, Live stream & $\begin{array}{l}\text { Network Advertising, Online } \\
\text { Shopping }\end{array}$ \\
\hline 5 & $\begin{array}{l}\text { Article, Video, Live } \\
\text { stream }\end{array}$ & $\begin{array}{l}\text { Paid Reading, Network } \\
\text { Advertising, Online Shopping }\end{array}$ \\
\hline 6 & $\begin{array}{l}\text { Article, Video, } \\
\text { Broadcast }\end{array}$ & Network Advertising \\
\hline 7 & Article & $\begin{array}{l}\text { Network Advertising, } \\
\text { Telemedicine, Online } \\
\text { Registration, Online Shopping }\end{array}$ \\
\hline 8 & Article & $\begin{array}{l}\text { Network Advertising, } \\
\text { Telemedicine, Online }\end{array}$ \\
\hline
\end{tabular}

Registration, Online Shopping, Insurance Service

Network Advertising, Paid

Reading

Network Advertising, Online

Shopping

Firstly, it can be concluded from Table I that the transmission mode and profit mode of public account of WeChat are diversified. From the perspective of transmission mode, public accounts of WeChat usually realize the communication through articles, but partial public accounts adopt video sharing, live stream, and broadcasting. From the perspective of profit mode, public accounts of WeChat prefer adopting various profit modes depending on the WeChat ecosystem. The network advertising placement into articles and videos is the most common technique, followed by online shopping. Regarding the profit mode of most representative public accounts, network advertising, paid reading, and health communication content issued by public accounts may be related, but telemedicine, online registration, and online shopping are not closely related to the health communication content as they are relatively independent supplementary service.

Table II Tiktok Account applied to health communication

\begin{tabular}{cll}
\hline Case & \multicolumn{1}{c}{$\begin{array}{c}\text { Transmission } \\
\text { Mode }\end{array}$} & \multicolumn{1}{c}{ Profit Mode } \\
\hline 1 & Video, Live stream & Online Shopping \\
2 & Video & Network Advertising \\
3 & Video & Network Advertising \\
4 & Video & Network Advertising \\
5 & Video & Online Shopping \\
6 & Video & Online Shopping \\
7 & Video & Online Shopping \\
8 & Video & Unclear \\
9 & Video & Online Shopping \\
10 & Video & Online Shopping \\
\hline
\end{tabular}

From Table II, Tiktok Accounts predominantly adopt videos and partial accounts resort to live stream at the same time. The most common profit mode is to place the online shopping link in videos. Besides, some accounts add links to promote the virtual content (including online stores, public accounts of WeChat and service, etc.), and it can be considered as a kind of network advertising.

Table III Sina Weibo Accounts applied to health communication

\begin{tabular}{cll}
\hline Case & \multicolumn{1}{c}{$\begin{array}{c}\text { Transmission } \\
\text { Mode }\end{array}$} & \multicolumn{1}{c}{ Profit Mode } \\
\hline 1 & Article, Video & Unclear \\
2 & Article, Video & Network Advertising \\
3 & Article, Video & Network Advertising \\
4 & Article, Video & Network Advertising \\
5 & Article, Video & Unclear \\
6 & Article, Video & Network Advertising, Online \\
7 & Article, Video & Shopping \\
8 & Article, Video & Unclear \\
9 & Article, Video & Unclear \\
10 & Article & Unclear \\
\hline
\end{tabular}

It can be seen from Table III that, the transmission mode of Sina Weibo mainly involves articles and videos. Although partial accounts rely on network advertising, and online shopping, the profit mode adopted by most 
accounts is unclear.

Table IV Health APPs applied to health communication

\begin{tabular}{|c|c|c|}
\hline Case & $\begin{array}{c}\text { Transmission } \\
\text { Mode }\end{array}$ & Profit Mode \\
\hline 1 & $\begin{array}{l}\text { Course, Article, } \\
\text { Video, Online } \\
\text { diary }\end{array}$ & Paid Course, Online Shopping \\
\hline 2 & $\begin{array}{l}\text { Article, Video, } \\
\text { Live Stream }\end{array}$ & $\begin{array}{l}\text { Telemedicine, Online Registration, } \\
\text { Online Shopping, Finance \& } \\
\text { Insurance }\end{array}$ \\
\hline 3 & $\begin{array}{l}\text { Course, Article, } \\
\text { Video, Online } \\
\text { diary }\end{array}$ & $\begin{array}{l}\text { Network Advertising, Paid Course, } \\
\text { Online Shopping }\end{array}$ \\
\hline 4 & $\begin{array}{l}\text { Article, Video, } \\
\text { Live Stream, } \\
\text { Online diary }\end{array}$ & Telemedicine, Online Registration \\
\hline 5 & Live Stream & $\begin{array}{l}\text { Telemedicine, Online Registration, } \\
\text { Physical Examination Service, } \\
\text { Online Shopping }\end{array}$ \\
\hline 6 & $\begin{array}{l}\text { Practical course, } \\
\text { Article, Social } \\
\text { Contact }\end{array}$ & Online Shopping \\
\hline 7 & Article & Paid Course \\
\hline 8 & Article, Video & $\begin{array}{l}\text { Telemedicine, Online Registration, } \\
\text { Online Shopping }\end{array}$ \\
\hline 9 & $\begin{array}{l}\text { Practical course, } \\
\text { Article, Video, } \\
\text { Live Stream }\end{array}$ & Paid Course \\
\hline 10 & Article & Telemedicine, Online Shopping \\
\hline
\end{tabular}

Table IV shows that the transmission mode and profit mode of representative health APP are diversified. In terms of transmission mode, there include articles and videos, and live stream rising in recent years are more common. Meanwhile, practical courses (objective, method, schedule and other information are available in APP, and select, alarm, help and other practical content are contained) in various forms and online diary has also become common transmission mode; in terms of profit mode, except paid course which largely depends on the appeal of health communication content in APP to the users, other profit contents are not closely related to the communication content, including telemedicine, online registration, online shopping, and financial \& insurance, etc.

\subsection{Operation Mode Analysis}

As new media applied to health communication has a huge base of followers or downloads, common transmission modes involve article, video, live stream, course with practical guidance, broadcast, online diary released on Moments (social feed of WeChat) or other SNS, of which, article and video still dominate; live stream has realized the most rapid development in recent years while the application of social contact content is relatively narrow and mainly limited to health APP.

For new media, common profit modes include network advertising, paid course, promotion of physical commodity or virtual content, and other services not directly related to health communication (like telemedicine and online registration), of which, network advertising and online shopping are the most common. At the same time, a few kinds of new media profit by continuously outputting high-quality content or resorting to promotion. In 4 kinds of common new media, the profit mode of health APP is the richest, including telemedicine, online registration, physical examination service, and financial insurance, but they are not closely related to the health communication content.

\section{Effect of New Media-based Health Communication}

When the diversified transmission mode and profit mode of new media have posed more opportunities and created more impetus for communicators to enter the field of health communication, false information will arouse the audience's anxiety and even affect the effect of new media-based health communication. For this reason, the authors focus on the impact of new media on different audiences' KAP.

\subsection{Subject and Method}

This survey is conducted by sending questionnaires to the smartphone users via Internet, and 300 copies of valid answers are collected. The sample's attribute is described as follows: 141 males, 159 Females; 2 subjects under 18 years old, 79 subjects between the age 18 and 79, 123 subjects between the age 30 and 59, 96 subjects above the age $60 ; 201$ subjects having health problems, 99 subjects not having health problems. The same set of questions (6 questions) is respectively configured for WeChat, Tiktok, Weibo, and health APP, and subjects shall respond on a 5point scale. However, "Whether you concern the health content?" and "Do you think the health content is reliable?" are to investigate the subjects' awareness and acceptance of the health communication content; "Do you think it will provide a reference for your maintenance/improvement of health conditions?", and "Do you think it can enhance your confidence in maintaining/improving health conditions?" are to investigate the subject's faith in improving their health conditions driven by the health communication content; "Will you accept the content and change your lifestyle?" and "Will you put it into practice and insist on it?" are to investigate the subjects' implementation of the health communication content. At last, scores (6 questions) of 4 kinds of new media will be respectively calculated to indicate the impact of 4 kinds of new media on their subjects' KAP; then, the total score (24 questions) will be calculated to show the overall impact of new media on the subjects' KAP. By regarding the audience's gender and health problems as the distinguishing standard, the score of each new media and the total score of new media are subject to the t-test; with the audience's age (excluding the minor) as the distinguishing standard, the variance analysis is conducted for the score of each new media and the total score of new media. SPSS 26 software is applied for these analyses.

\subsection{The Impact of New Media on Different Groups' KAP}

According to the investigation result, regarding the overall impact of 4 kinds of new media on the KAP, there are no significant differences among people of different genders 
or ages, but there are significant differences between people with health problems and the ones without $(t=$ $3.049, p<.005)$.

Through surveying the specific impact of each new media, some subtle differences can be spotted. Specifically, WeChat's impact on the KAP of the groups of different genders and ages is not significantly different, but the significant difference $(t=-1.991, p<0.05)$ can only be found between the group having health problems $(M=16.28, S D=5.231)$ and the group not $(\mathrm{M}=17.56$, $\mathrm{SD}=5.145)$; the difference of Tiktok's impact on the KAP of the groups of different ages is not significant, but the difference between males $(\mathrm{M}=14.56, \mathrm{SD}=6.576)$ and females $(M=16.31, S D=6.317)$ is statistically significant $(\mathrm{t}=-2.053, \mathrm{p}<0.05)$ as well as the difference $(\mathrm{t}=-2.495$, $\mathrm{p}<0.05)$ between the group having health problems $(\mathrm{M}=$ $14.78, \mathrm{SD}=6.105)$ and the group not $(\mathrm{M}=17.04, \mathrm{SD}=$ 7.008); the difference of Weibo's impact on the KAP of the groups of different genders and ages is not statistically significant, but the difference between the group having health problems $(\mathrm{M}=14.65, \mathrm{SD}=6.155)$ and the group $\operatorname{not}(\mathrm{M}=17.11, \mathrm{SD}=6.872)$ is statistically significant $(\mathrm{t}=$ $-2.541, \mathrm{p}<0.05)$; the difference of health APP's impact on the KAP of the group having different ages is not significant, but the obvious difference can be observed between the group having health problems $(\mathrm{M}=17.10, \mathrm{SD}$ $=6.126)$ and the group not $(\mathrm{M}=19.22, \mathrm{SD}=6.319)$ while the difference between various age groups is statistically significant (see Table V, and Table VI).

Table V Descriptive Statistics of the Effect of Health APP on KAP of People in Different Age Groups

\begin{tabular}{ccccc}
\hline Age & $\mathrm{N}$ & aver. & SD & SEM \\
\hline $18-29$ & 56 & 118.63 & 37.305 & 4.985 \\
$30-59$ & 59 & 117.42 & 39.504 & 5.143 \\
Over 60 & 54 & 113.69 & 36.481 & 4.965 \\
total & 169 & 116.63 & 37.664 & 2.897 \\
score & & & & \\
\hline
\end{tabular}

Table VI One-way ANOVA of Effect of Health APP on KAP of People in Different Age Groups

\begin{tabular}{ccccc}
\hline & Sum of Squares & $d f$ & Mean Square & F \\
\hline Between Groups & 743.635 & 2 & 371.818 & 10.447 \\
Within Groups & 7047.201 & 198 & 35.592 & .000 \\
Total & 7790.836 & 200 & & \\
\hline
\end{tabular}

\subsection{Analysis of Transmission Effect}

According to the investigation result and the impact of new media-based health communication on the KAP of different audiences, the impact of new media on the group not having health problems is significantly higher than that on the group having health problems while the impact of new media on the groups of different ages and genders is not significantly different; through comparing the impact of 4 kinds of new media on the KAP of different audiences, it can be found that the impact of 4 kinds of new media on the group not having health problem is significantly higher than that on the group having health problems. The impact of Tiktok and other video sharing APP on the female's KAP is higher than that on the male's while the impact of health APP on the KAP of the persons above 60 years old is significantly lower than that on persons between the age 18 and 20 and persons between the age 30 and 59 .

\section{The Audience's Feedback on New Media-based Health Communication}

After the operation mode and transmission effect of all kinds of new media are surveyed, special effort is made to further investigate the audience's feedback in this research to combine the objective facts with the subjective feelings and make a comprehensive analysis on the current situation of new media-based health communication.

\subsection{Respondent and Method}

During the questionnaire survey as mentioned in 3.1, multiple-choice questions are also configured to investigate the audience's feedback. Partially, the questionnaire has referred to the investigation result of operation mode in 2.5, and the audience's comments and expectation on new media are surveyed by various questions concerning "the way to gain health information", "transmission mode they concern about", "comments on the health content of new media", "comments on the commercialization of new media-based health communication" and "acceptable commercialized health content in new media". Then, a simple statistic will be conducted for questionnaire scores, on which basis, the content analysis is made. The sample's attribute is listed in III A.

\subsection{The Audience's Comments and Expectation on New Media}

Based on the investigation result of the multiple-choice question "the way to gain information about health/health information", the number of people obtaining health information via WeChat is the largest (192), successively followed by people getting health information from others (122), people via books and newspapers (119), people via health APP (100) and people via TV \& broadcasting (99).

Meanwhile, 74 subjects refuse to be exposed to health knowledge in any form via smartphones.

The investigation result of "transmission mode they concern about" shows that: the number of people reading articles is the largest (152), respectively followed by 
people viewing videos (131), people attending courses with practical guidance (97), and people exposed to online diaries (85).

The investigation result of "comments on the health content in new media" shows that: the number of people who think "it is difficult to confirm whether the content is reliable" is the largest (157), respectively followed by people thinking "it is hard to stick to"(78), people thinking "it is instructive but hard to arouse the determination to take action" (72) and people thinking "few deserve their attention" (70). Also, 85 people express that they "will not take the initiative to use any APP to obtain any health content".

The investigation result of "Comments on the Commercialization of New Media-based Health Communication" shows that the number of people "concerning about communicators' issuing of false content for the sake of profit" is the largest (144), respectively followed by people expressing "not worry about it, because the provision of high-quality is based on the communicator's profit" (65) and people expressing "not worry about it, because the communicator's profiting may not influence the content" (43).

The investigation result of "Acceptable Commercialized Health Content in New Media" shows that the number of people "disliking the commercialized health content" is the largest (108), respectively followed by people "receptive to the APP interface advertising" (96), people "willing to pay for the listening of content with reference significance" (77) and people "receptive to the shopping link added in the APP interface or article/video/live stream" (58).

\subsection{Analysis of Transmission Effect}

From corresponding investigation results, it can be concluded that WeChat plays a significant role in health communication among smartphone users, and health APP has also become an important health communication means which is comparable to books, newspapers, and TV $\&$ broadcasting. However, many shortcomings can also be discovered from the information's credibility, the behavior's duration, and the effectiveness of guiding behaviors in terms of the new media-based health communication content. In particular, people's concern about health content's credibility is obvious. Besides, the investigation finds that, although about $50 \%$ of audiences are dissatisfied with and even resist the profiting via health communication and concern about the communicator's issuing of biased or untrue content to profit quickly, more than $30 \%$ of audiences express their understanding of the commercialized operation. Besides, the specific profit mode, moderate advertising placement, and paid listening of high-quality content have been widely accepted. Also, the combination of communication content with online shopping, telemedicine, and online registration are acceptable to a significant portion of audiences.

\section{Discussion}

Through analyzing the operation mode, effect, and feedback of new media-based health communication based on the empirical investigation result, the following three noticeable problems can be discovered:

\subsection{Operation Mode needs to be optimized}

Firstly, the new media-based health communication not only possesses a huge base of audiences but also involves a variety of transmission modes and diverse profit modes. Nevertheless, the traditional transmission mode like article and video still dominates in most forms of media, so no remarkable difference in transmission modes can be found between traditional media and new media. Compared with traditional media, the above-mentioned new media have not displayed any obvious advantage in guiding health behaviors. Instead, the transmission mechanism featuring "issuing first, reviewing after" may result in the flooding of false information [8]. Secondly, heavy dependence on the profit mode based on network advertising and online shopping may prompt communicators to exaggerate and even start a rumor for the improper pursuit of click-through rate and short-term promotion. Although the profit mode based on the subscriber's paid listening can encourage the practitioner to continuously output the high-quality health communication content, a further increase is required in the number of current new media adopting this profit mode.

\subsection{For partial groups, an ideal effect cannot be achieved}

Firstly, the group not having health problems is more liable to the impact of new media-based health communication, which may be interpreted from the perspective of the positive role played by the new mediabased health communication. As this investigation does not involve the analysis of the causal relationship between data, further research is required. Corresponding investigation results show that, regarding the health communication to the group having health problems, it is necessary to further optimize the specific transmission mode and content. Secondly, although the traditional vide upholds that young people are more receptive to new media [9], the investigation result indicates that, if the scope is limited to smartphone users, the impact of new media-based health communication on the elderly is not significantly lower than that on other age groups, which proves the feasibility of conducting health communication for the elderly based on new media; thirdly, if further analysis is made to 4 kinds of new media, the specific difference can be found existent between them. Accordingly, the impact of Tiktok on females is significantly higher than that on males while the impact of health APP on the elderly is remarkably lower than that on other groups, which indicates that in-depth research is required to analyze the specific health communication strategies. 


\subsection{The Audience's Comments and Expectation on New Media}

Firstly, although new media has played an important role in health communication, a significant portion of audiences are passive in receiving information without a strong will of acquiring the health-related content, making it difficult for them to obtain the target information. Secondly, the new media-based health communication is deemed as insufficient in credibility and invalid in effectively and continuously changing the user's health behaviors and living habits. Thirdly, the commercialization of health communication may arouse the user's concern about the transmission content, but a significant portion of audiences express their understanding of the moderate commercialization. Therefore, the new media's credibility and effectiveness are badly in need of improvement, on which basis, the standardized commercial operation is taken into consideration

\section{Suggestion}

Considering the above-mentioned three problems, the corresponding improvement must be made from the following aspects to achieve the innovation, or to optimize the effectiveness of health communication:

\subsection{Optimizing the Operation Mode}

It is necessary to encourage the development of new media based on the novel operation mode; by continuously outputting the high-quality content, Subscribe, Shopping, Promotion, and other services can be organically combined with the health communication-related content, preventing communicators from resorting to the publicity stunt.

\subsection{For partial groups, an ideal effect cannot be achieved}

The effect of existing new media varies obviously between different groups of audiences. After in-depth user research is carried out to master the audience's demands and behaviors, effective transmission modes will be selected and the targeted transmission content created according to user persona, usage scenario, and behavioral change theory. For example, the investigation result indicates that, despite the extensive influence, as the richest transmission mode and the most diversified profit mode, health APP has no significant impact on the elderly. Hence, emphasis shall be placed on the design iteration based on user experience for the elderly.

\subsection{For partial groups, an ideal effect cannot be achieved}

Although the health communication's credibility causes a variety of worries against the background of commercialization, the guarantee of credibility not only requires the new media practitioners' self-improvement and self-discipline but also need to make full use of external forces to regulate the commercial operation of new media-based health communication through strengthening relevant departments' regulatory system geared to new media and perfecting the verification mechanism of authoritative media and professionals.

\section{Acknowledgement}

Supported by "the Fundamental Research Funds for the Central Universities”, No. 30920021204

\section{References}

1. E. M. Rogers, "The field of health communication today," American Behavioral Scientist, vol. 38, pp. 208-214, 1994

2. E. M. Rogers, "The field of health communication today: An up-to-date report," Journal of Health Communication, vol. 1, pp. 15-23, Jan-Mar 1996.

3. Y. Fan, S. Zhang, Y. Li, Y. Li, T. Zhang, W. Liu, et al., "Development and psychometric testing of the Knowledge, Attitudes and Practices (KAP) questionnaire among student Tuberculosis (TB) Patients (STBP-KAPQ) in China," BMC infectious diseases, vol. 18, p. 213, May 82018.

4. R. K. Thomas, "Introduction to health communication," in Health communication, R. K. Thomas, Ed., ed Boston, MA: Springer US, 2006, pp. 1-7.

5. R. Wei, "New technology research," in Research methods in communications, D. Sloan and S. Zhou, Eds., ed Northport, AL: Vision Press, 2008, pp. 389405.

6. C. N. Li, New media \& health communication. Beijing: Peking Union Medical College Press, 2019.

7. W. Xie, "An analysis of fragmented reading and its social impact on college students in the era of new media," Journal of Contemporary Educational Research, vol. 3, no.3, pp. 33-37, 2019.

8. C. M. Pulido, L. Ruiz-Eugenio, G. Redondo-Sama, and B. Villarejo-Carballido, "A new application of social impact in social media for overcoming fake news in health," International Journal of Environmental Research and Public Health, vol. 17, p. 2430, 2020.

9. S. Román-García, A. Almansa-Martínez and M. CruzDíaz, "Adults and Elders and their use of ICTs. Media Competence of Digital Immigrants", Comunicar, vol. 24, no. 49, pp. 101-110, 2016. 